\title{
Vancomycin-Resistant Van A Phenotype Enterococcus faecalis: First Case in Minas Gerais State and Epidemiological Considerations
}

\author{
Rosineide Marques Ribas ${ }^{1}$, Ana Lúcia da Costa Darini ${ }^{2}$, Tomaz Aquino Moreira ${ }^{1}$, Claudete Freitas ${ }^{1}$ and Paulo P. Gontijo Filho $^{1}$ \\ ${ }^{1}$ Federal University of Uberlândia, Laboratory de Microbiology; Uberlândia, MG; ${ }^{2}$ Special Laboratory of Bacteriology and Molecular \\ Epidemiology, Pharmaceutical Schiences School; Ribeirão Preto/USP; Ribeirão Pretp, SP, Brazil
}

\begin{abstract}
We report the first case of vancomycin-resistant Enterococcus faecalis with VanA phenotype and vanA genotype isolated from a surgical patient in a general Hospital in Uberlândia, state of Minas Gerais, Brazil. Key-Words: Nosocomial infections, antibiotic resistance, VRE.
\end{abstract}

Current surveillance reveals steadily increasing rates of resistance to vancomycin among Enterococcus isolates from patients in United States ICUs ("Intensive Care Units") who have nosocomial infections [1]. Outbreaks of vancomycinresistant Enterococcus (VRE) infection are also frequent in nearly one-third of US hospitals [2]. Though most clinical isolates of Enterococcus spp., whether glycopeptide susceptible or resistant, indicate colonization rather than infection, VRE are undoubtedly significant pathogens [3].

The first case in Brazil was reported only in 1998 [4] from a nine-year-old girl with aplastic anemia, who died from sepsis associated with VanA Enterococcus faecium. Since the early 2000s, a large number of cases were reported in hospitals with 200-500 beds in Rio de Janeiro, São Paulo and Porto Alegre [5,6].

We describe the first case of a patient with infection by VRE in Minas Gerais; we examined epidemiological aspects, such as known-risk factors for these infections and routine surveillance made with periodic bowel culture surveys.

\section{Case Report}

A 30-year-old female patient victim of a traffic accident was hospitalized on August 4, 2003, in the Traumatic/ Orthopedic Ward of the Hospital of the Universidade Federal de Uberlândia (Federal University of Uberlândia) in the state of Minas Gerais, Brazil. She was submitted to surgeries of osteosynthesis and bladder reconstitution on the same day and was found to have a urinary infection; the patient was prophylactically treated with the antibiotics ceftriaxone, cephalotin, and vancomycin. On August 10, urine culture identified vancomycin-resistant Enterococcus faecalis. The antibiotic treatment was immediately changed to linezolid, and the patient left the hospital on August 21.

\section{Bacteriology}

Urine culture showed Gram-positive cocci, which were catalase negative. The organism was positive for growth in

Received on 18 February 2007; revised 26 July 2007.

Address for correspondence: Dr. Rosineide Ribas. R. Nordau Gonçalves Melo, no 1245, B. Santa Mônica - Uberlândia/MG - Zip code: 38408218 - E-mail: rosi_ribas@yahoo.com.br / Contact phone number: 55 (34) 3236-8551.

The Brazilian Journal of Infectious Diseases

2007;11(4):439-440. (C) 2007 by The Brazilian Journal of Infectious Diseases and Contexto Publishing. All rights reserved.
$6.5 \% \mathrm{NaCl}$, hydrolysis of bile esculin, sorbitol, telurite, and pyruvate, and for the presence of pyrrolidonyl-arylamidase (PYR).

Based on these results, the strain was characterized as Enterococcus, and species identification was confirmed by PCR. Antibiotic susceptibility was determined with a disk diffusion test and Mueller-Hinton agar for the following antibiotics: vancomycin $(6 \mu \mathrm{g} / \mathrm{mL})$, gentamicin $(500 \mu \mathrm{g} / \mathrm{mL})$ and streptomycin $(2,000 \mu \mathrm{g} / \mathrm{mL})$.

The minimum inhibitory concentration (MIC) was determined by the $\mathrm{E}$ test method, with the following results: vancomycin $>256 \mu \mathrm{g} / \mathrm{mL}$. The VanA gene was determined by the PCR method. No b-lactamase production was demonstrated by the nitrocefin test.

\section{Surveillance Cultures}

Surveillance specimens (rectal swabs) were plated onto a screening plate with selective media brain-heart infusion agar containing $6 \mu \mathrm{g} / \mathrm{mL}$ of vancomycin. The study was conducted through a day-prevalence survey during a three-year period from October 2003 to October 2006. All patients attended at the adult intensive-care unit were eligible for inclusion in the study.

\section{Discussion}

In hospitals, the reservoir of Enterococci is the bowels of patients. Cross-infection and clusters of infection occur, and resistant strains can be transmitted via staff hands and occasionally by the environment $[7,8]$. As with many other antimicrobial-resistant organisms, colonization is more frequent than true infection $[7,8]$. The emergence of Enterococci with acquired vancomycin resistance is a consequence of the appearance and spread of transposons encoding VanA phenotype [9]. This usually occurs within environments where there is heavy usage of glycopeptides and/or cephalosporins $[10,11]$. Preceding therapy with some antibiotics, including those containing active agents against anaerobes, such as metronidazol and clindamycin, has also been implicated $[12,13]$. Our patient had been treated with cefalosporins and vancomycin.

The risk of VRE acquisition is proportional to the length of hospital stay [14], care in teaching hospitals and in hospitals with a high number of beds ( $>500)$, as well as in renal, liver, hematology, oncology, and transplant wards, and especially, 
intensive care units $[10,15]$. Apart from the use of antimicrobial agents and inpatient care in particular units, other risk factors for VRE colonization and infection that have been identified in other studies include malignancy, use of enteral feeding (tube feeding), gastric acid suppression, use of central venous lines, increasing morbidity as measured by the Acute Physiology and Chronic Health Evaluation (APACHE) score, neutropenia, renal failure, mechanical ventilation, organ transplantation and hematological malignancy [3]. Our patient was a surgical case. She was interned in the ICU, and her condition was very serious.

Nosocomial VRE colonization and infection seems to be much more frequent in the USA than in Europe [16]; in the former, the VanA phenotype is found in the bowels of normal people in the community, in frozen meats and animal carcasses, and in the bowels of animals fed with the glycopeptide avoparcin as a food supplement [17]. Administration of vancomycin may result in subsequent emergence of VRE following hospital admission [18], but it may also spread by cross-infection among hospital patients [13]. The epidemiological Brazilian situation seems to be closer to that of Europe than the one observed in the US, considering the lack of detection of victims in the community [19]. Non-use of glycopeptides as growth promoters also should be considered. Also, empirical use of vancomycin is the habitual practice, without traditional preventative measures for hospital infections [20].

Until recently, VRE were rarely isolated in Brazilian hospitals [21]; but in the last years there has been an increasing incidence of VRE in many hospitals in the state of São Paulo, apparently due to dissemination of a resistant clone from Rio de Janeiro [5].

In spite of risk factors for VRE that clearly provide the environment in which this organism could flourish, such as use of vancomycin and cephalosporins, ICU admission and prolonged hospitalization, and mainly, low compliance with infection-control procedures, including ineffective hand washing practices, we only isolated one case of VRE after three years of surveillance.

\section{Acknowledgments}

The authors thank Izabel Cristina V. Palazzo for her help in van gene detection and bacterial identification and Joseane Cristina Ferreira for the pulsed field gel electrophoresis.

\section{References}

1. National Nosocomial Infections Surveillance (NNIS) System Report, data summary from January 1992 through June 2004, issued October 2004. Am. J. Infect Control 2004;32:470-85.

2. Diekema D.J., BootsMiller B.J., Vaughn E.V., et al. Antimicrobial resistance trends and outbreak frequency in United States hospitals. 2004:38:78-84.

3. Brown D.F.J., Brown N.M., Bookson B.D., et al., National glycopeptide-resistant enterococcal bacteraemia surveillance working group report to the Department o Health - august 2004. J Hosp Inf 2006;62(Suppl 1):S1-S27.
4. Dalla Costa L.M., Souza D.C., Martins L.T.F., et al. Vancomycinresistant Enterococcus faecium: first case in Brazil. Braz J Infect Dis 1998:2:160-3.

5. Camargo I.L., Del Peloso P.F., Da Costa Leite C.F., et al. Identification of an unusual VanA element in glycopeptideresistant Enterococcus faecium in Brazil following international transfer of a bone marrow transplant patient. Can J Microbiol 2004;50:767-70.

6. Zanella R.C., Valdetaro F., Lovgren M., et al. First confirmed case of a vancomycin-resistant Enterococcus faecium with vanA phenotype from Brazil: isolation from a meningitis case in São Paulo. Microb Drug Resist 1999;5:159-62.

7. Zervos M.J., Terpenning M.S., Schaber D.R., et al. High level aminoglycoside-resistant enterococci-colonization of nursing home and acute care hospital patients. Arch Intern Med 1987:1591-4.

8. Rhinehart E., Smith N.E., Wennersten C., et al. Rapid dissemination of b-lactamase-producing, aminoglycosideresistant Enterococcus faecalis among patients and staff on an infant-toddler surgical ward. N Engl J Med 1990;323:1814-8.

9. Clark N.C., Cooksey E.C., Hill B.C., et al. Characterization of glycopeptide-resistant enterococci from US hospitals. Antimicrob. Agents Chemother 1993;37:2311-7.

10. Husni R., Haschem R., Hanna H. Risk factors for vancomycinresistant Enterococcus (VRE) infection in colonized patients with cancer. Infect Control Hosp Epidemiol 2002;23:102-3.

11. Handwerger S., Raucher B., Altarac D., et al. Nosocomial outbreak due to Enterococcus faecium highly resistant to vancomycin, penicillin and gentamicin. Clin Infect Djis 1993;16:750-5.

12. Byers K.E., Anglim A.M., Anneski C.J., et al. A hospital epidemic of vancomycin-resistant Enterococcus: risk factors and control. Infect Control Hosp Epidemiol 2001;22:140-7.

13. Gerding D.N. Is there a relationship between vancomycin-resistant enterococcal infection and Clostridium difficile infection? Clin Infect Dis 1997;25(Supppl 2):206-10.

14. Montecalvo M.A., de Lencastre H., Carraher M., et al. Natural history of colonization with vancomycin-resistant Enterococcus faecium. Infect Control Hosp Epidemiol $1995 ; 16: 680-5$.

15. Livornese L.L., Dias S., Samel C., et al. Hospital-acquired infection with vancomycin-resistant Enterococcus faecium transmitted by electronic thermometers. Ann Intern Med 1992; $117: 112-6$.

16. Goossens H. Spread of vancomycin-resistant enterococci: differences between United States and Europe. Infect control Hosp Epidemio 1998; 19:546-51.

17. Bates J. Epidemiology of vancomycin-resistant enterocci in the community and the relevance of farm animals to human infection. J Hosp Infect 1997;37:89-101.

18. Endtz H.P., van den Braak N., van Belkim A., et al. Fecal carriage of vancomycin-resistant enterococci in hospitalized patients and those living in the community in The Netherlands. J Clin Microbiol 1997;35:3026-31.

19. Silva C.R.M. Pesquisa de enterococcus resistente aos glicopeptídeos em humanos, aves e ambiente, na cidade de Uberlândia. Dissertação de Mestrado. Curso de Pós-graduação em Genética e Bioquímica. Universidade Federal de Uberlândia, MG. 2000.

20. Couto H.G., Lelles C.C.V., Lima H.V., et al. Vancomycin use in a Brazilian University hospital: Comparisons with hospital infection control practices advisory committee guidelines. Braz J Infec Dis 1999;3:139-43.

21. Cereda R., Sader H., Sejas L., et al. Enterococcus faecalis resistant to vancomycin and teicoplanin (VanA phenotype) isolated from a bone marrow transplanted patient in Brazil. Braz J Infect Dis 2001;5(1):40-6. 